\title{
In Vitro and ex Vitro Adventitious Root Formation in Asian Jasmine (Trachelospermum asiaticum) I. Comparative Morphology
}

\author{
R.C. Apter ${ }^{1}$, E.L. McWilliams ${ }^{2}$, and F.T. Davies, Jr. ${ }^{2}$ \\ Department of Horticultural Sciences, Texas A\&M University, College Station, TX 77843-2133
}

Additional index words. developmental anatomy, micropropagation, tissue culture

\begin{abstract}
One-node explants and one-node stem cuttings of Asian jasmine [Trachelospermum asiaticum (Siebold \& Zucc.) Nakai] were rooted, respectively, in vitro [tissue culture (TC)] or by conventional macropropagation (MACRO). The TC and MACRO stem bases were then analyzed for differences in the time-course sequence of 1) root primordia initiation and development and 2) adventitious root xylem development and root-to-shoot xylem connections. Early root primordia were observed at Day 3, and, by Day 7, root-to-shoot xylem connections were equally developed in TC and MACRO systems. Continued development and emergence of adventitious roots were observed at Days 8 to 10. At Days 13 and 18, when viewed using scanning electron microscopy, TC root hairs were morphologically thicker and one-third to one-half the length of MACRO root hairs. There was no apparent difference in root-hair density. Inferior TC root-hair length may be a factor in the acclimation of TC-generated plantlets.
\end{abstract}

Successful acclimatization (Stage IV) is one of the primary factors limiting commercial tissue culture production systems (Hartmarm et al., 1990). Anatomical changes induced in leaves by the tissue culture (TC) environment have been investigated extensively (Brainerd et al., 1981; Donnelly and Vidaver, 1984a, 1984b; Smith et al., 1986). TC conditions, while highly promotive for shoot proliferation and plantlet growth, are antagonistic to the formation of normal leaf anatomy (Ziv, 1986). In addition, few comparisons have been made between adventitious roots formed in agar under aseptic conditions and roots formed under conventional, nonsterile conditions [macropropagated (MACRO)]. In plantlets of cauliflower (Brassica oleracea L.), vascular connections between roots and shoots were poorly formed and narrow (Grout and Aston, 1977). The vascular connections became more extensive during acclimation, but water uptake was reportedly less than with seedlings. Studies of TC-formed roots during acclimatization are needed to determine how well they function and adapt to ex vitro conditions and how their physiology is affected by TCinduced changes in anatomy and morphology (Zimmerman, 1988).

Using Asian jasmine as a model system, due to the ease with which it is rooted, our objective was to compare developmental morphology of adventitious roots from TC explants and MACRO cuttings. Emphasis was placed on the sequence of initiation and development of root primordia, the development of the root-toshoot vascular junction, and root-hair morphology.

\section{Materials and Methods}

Plant culture and environmental conditions. Explants and cuttings were collected from container-grown, glasshouse-maintained stock plants produced under natural daylength, supplemented as required with a 2-h night interruption with incandescent lighting to maintain long-day conditions. Maximum daytime irra-

Received for publication 12 Aug. 1992. Accepted for publication 25 Mar. 1993. We greatly appreciate the technical assistance of Sharon A. Duray and Matt Kent. We thank Delores Soto for typing the manuscript. The cost of publishing this paper was defrayed in part by the payment of page charges. Under postal regulations, this paper therefore must be hereby marked advertisement solely to indicate this fact. ${ }^{1}$ Graduate student. Present address: Dept. of Animal Sciences, Texas A\&M Univ., College Station, TX 77843

${ }^{2}$ Professor. diance [photosynthetic photon flux (PPF)] was $900 \mu \mathrm{mol} \cdot \mathrm{s}^{-1} \cdot \mathrm{m}^{-2}$, as measured at plant height with a quantum sensor (model LI-189; LI-COR, Lincoln, Neb.). Night temperatures in the glasshouse were $23 \pm 3 \mathrm{C}$, with a daytime minimum and maximum of 25 and 30C, respectively. Thirty stock plants from the same source plant were grown in a composted 4 pine bark : 1 sand mixture $(\mathrm{v} / \mathrm{v})$ in 2.6-liter containers. The medium was amended with gypsum and dolomite at $3 \mathrm{~kg} \cdot \mathrm{m}^{-3}$, with fritted trace elements (W.R. Grace, Fogelsville, Pa.) at $74.2 \mathrm{~g} \cdot \mathrm{m}^{-3}$. Stock plants were fertilized weekly with Peters $20 \mathrm{~N}-8.8 \mathrm{P}-16.6 \mathrm{~K}$ (2.0 g.liter $\left.{ }^{-1}\right)$ and every 3 weeks with soluble trace element mix (W.R. Grace) at $7.4 \mathrm{~g} \cdot$ liter $^{-1}$. TC explants and MACRO cuttings were identical in size and length and consisted of one-node stem sections bearing two leaves and the associated internodal stem below the node. Explants and cuttings were always collected from stock plant terminal nodes 4 to 7 (numbered acropetally from the crown). Explants and cuttings were later trimmed to a length of $1.5 \mathrm{~cm}$. Propagation with both systems was done under controlledenvironmental conditions at 22 $\pm 2 \mathrm{C}$ with a $16-\mathrm{h}$ photoperiod of $150 \mu \mathrm{mol} \cdot \mathrm{s}^{-1} \cdot \mathrm{m}^{-2}$ (PPF) provided by cool-white fluorescent lamps. Explants and cuttings were not treated with auxin.

TC system. Explants were taken from stock plants and trimmed to one-node segments before sterilization, which consisted of 1) submersion and rinsing for $1.5 \mathrm{~h}$ in running tap water, 2) surface sterilization in $70 \%$ ethanol for $1 \mathrm{~min}, 3$ ) an agitated soak in $0.53 \%$ (by volume) sodium hypochlorite containing 1\% (by volume) Liquinox (Alconox, New York) for $15 \mathrm{~min}$, and 4) three rinses in sterile, distilled water. Under aseptic conditions, and before insertion into $25 \times 150$-mm tubes, the explants were trimmed further to yield a stem segment $\approx 1.5 \mathrm{~cm}$ long bearing two leaves. Explants were cultured on woody plant medium (WPM) (Lloyd and McCown, 1980) containing $7 \mathrm{~g}$ agar (Difco Bacto; Difco Laboratories, Detroit) and $30 \mathrm{~g}$ sucrose/liter, but no phytohormones. The medium was adjusted to $\mathrm{pH} 5.5$ and sterilized in an autoclave at $121 \mathrm{C}$ for $15 \mathrm{~min}$. The design was a randomized complete block, with each treatment (i.e., propagation system) represented once within each block by 10 experimental units (10 sampling periods) of 12 cuttings each $(\mathrm{n}=12)$. There were three blocks.

MACRO system. MACRO cuttings were the same size as the TC explants. Before inserting the cuttings, perlite in $24.8 \times 15.8 \times 8.3$ $\mathrm{cm}$ trays was moistened with $\approx 1$ liter of full-strength WPM, 
lacking sucrose and agar, and allowed to drain. Trays were placed in sealed, clear polyethylene bags supported above the cuttings by wire hoops. Croups of cuttings representing each sampling date were tagged randomly to avoid bias during sample selection. Twice during the 18-day period (Days 7 and 14) the medium surface was misted with distilled water to prevent desiccation. The experimental design was as outlined for the TC system.

Anatomical and morphological analyses. Explants and cuttings were placed in TC or MACRO systems on Day 0; samples were taken on Days $0,1,3$, and $5(\mathrm{n}=12$ per treatment per sampling day), Days 7 to $10(\mathrm{n}=15)$, and Days 13 and 18 [n = 12 for light microscopy and $n=6$ for scanning electron microscopy (SEM)] and prepared for either light microscopy or SEM.

For light microscopy, samples were removed from their respective medium and the roots were gently washed of any adherent material and fixed in formalin-acetic acid-ethyl alcohol (FAA). When all samples had been collected, the basal $10 \mathrm{~mm}$ of each cutting was removed, along with any attached roots, and dehydrated with an ethanol-tertiary butyl alcohol series and embedded in Paraplast-Plus (Lancer, St. Louis). Blocks containing stem pieces with both end surfaces exposed were soaked for $12 \mathrm{~h}$ (overnight) in distilled water in vacuo to soften the tissues before sectioning (Davies et al., 1982). Serial cross- and longitudinal sections were cut at $11 \mu \mathrm{m}$ and stained with safranin and fast green.
The bases of cuttings and explants sampled before root emergence were sectioned to observe internal changes associated with the initiation of root primordia. Development of xylem at the root-toshoot interface (shoot-root junction) was also observed from primordia initiation through primordia elongation and root emergence.

For SEM of root hairs, freshly harvested roots from TC and MACRO treatments were carefully washed and fixed in FAA. After 24-h, the FAA was decanted and the roots were stored in $70 \%$ ethanol. Samples were critical-point dried in $\mathrm{CO}_{2}$, mounted on aluminum disks, and sputter-coated with gold. Roots were viewed at $\times 50$ and $\times 75$ magnification on a scanning electron microscope (model JSM-T330A; Jeol Techniques, Tokyo) with an accelerating voltage of $15 \mathrm{kv}$.

\section{Results and Discussion}

Rooting, defined as visible emergence of root primordia, occurred more rapidly with MACRO cuttings; $50 \%$ was rooted at Day 7 compared to only $7 \%$ of TC explants. However, by Day 9, nearly $75 \%$ rooting occurred in both treatments, and, by Day 18, $100 \%$ had rooted.

Light microscopy. No discernible changes were evident in either treatment by Day 1 in the phloem and cambial regions (Fig. 1A). By Day 3, however, early root primordia were present in both

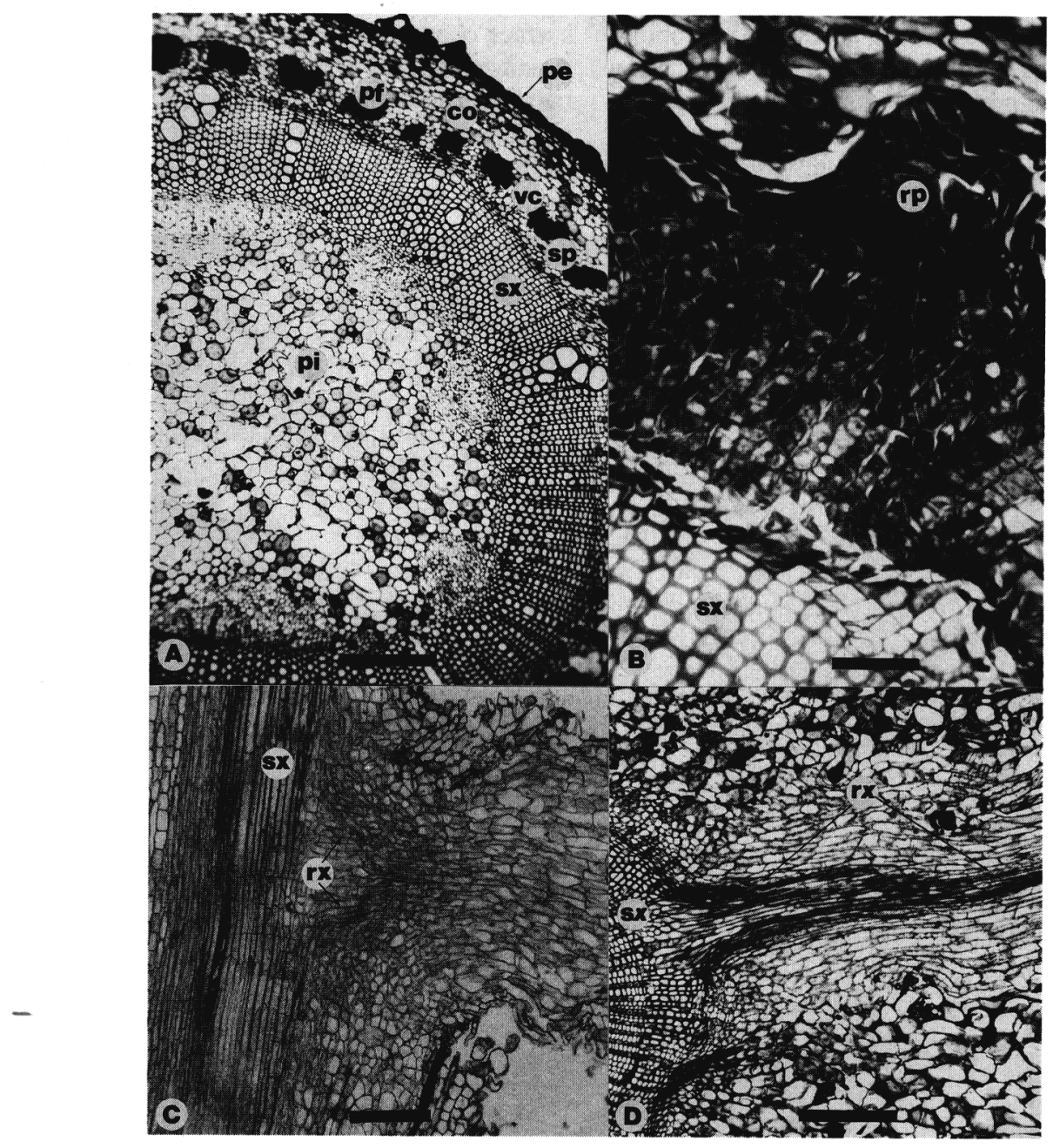

Fig. 1. Photomicrographs of the basal portions of in vitro stem sections of Asian jasmine. (A) Day 0: basal cross section (bar $=50 \mu \mathrm{m})$; (B) Day 5: basal cross section with a visible root primordium (bar $=10 \mu \mathrm{m}) ;($ C) Day 7: longitudinal section with substantial xylem connections $(\mathrm{bar}=50 \mu \mathrm{m}) ;(\mathrm{D})$ Day 10: cross section of stem base with further development of root-to-shoot vascular connection $(\mathrm{bar}=50 \mu \mathrm{m})$. $\mathrm{pi}=\mathrm{Pith}, \mathrm{rp}=$ root primordium, $\mathrm{rx}=$ adventitious root $\mathrm{xylem}, \mathrm{sx}=\mathrm{shoot}$ secondary xylem, $\mathrm{vc}=$ shoot vascular cambium, $\mathrm{sp}=$ shoot secondary phloem, $\mathrm{pf}=$ shoot phloem fibers, $\mathrm{co}=$ shoot cortex, $\mathrm{pe}=$ shoot periderm . 
treatments. Primordia appeared as small groups of 25 to 75 cells containing darkly stained cytoplasm and nuclei, and, in both treatments, they originated just external to the cambium in the phloem. In some preparations, little cellular change had occurred, whereas, in other sections, early transitional states between lessand more-developed primordia were evident. By Day 5, welldefined root primordia with darkly staining cytoplasm and nuclei were present (Fig. 1B). Early root primordia xylem development and occasional root penetration through the periderm occurred by day 7. Early xylem development was evident at the root primordium base and was connected to the secondary xylem of the shoot system. These immature primary xylem cells appeared to be helical in form (Esau, 1977) and their nuclei were still distinguishable. By Day 7, root primordia had substantial xylem development and vascular connections with the shoot secondary xylem (Fig. 1C). Continued elongation of the emerging roots and further xylem development within the adventitious root and at the root-to-shoot interface occurred at Days 8 to 10 (Fig. 1D).

Developmentally and anatomically, no difference existed between the two propagation systems, other than the initial rate of rooting; hence, only photomicrographs of TC basal explant sections are presented (Fig. 1). While TC explants exhibited a 1 to 2 day lag in root primordia initiation, by Day 9 these differences were no longer evident. There was no evidence in either treatment that xylem elements were discontinuous between the elongating primordia and the base of the primordia adjacent to the cambium after 8 to 10 days (Fig. 1D). Our postulate that TC root initiation processes are affected in a manner analogous to that seen with in vitro-formed leaves is not supported by these observations. Ziv (1986) concluded that TC conditions, while highly promotive for rapid growth, are antagonistic to the formation of normal leaf anatomy. Donnelly et al. (1985) determined that leaf anatomical alterations seen early in ontogeny are not reversible once initiated. These conclusions, while applicable to TC-formed leaves, may not be appropriate for TC-formed roots of Asian jasmine.

Researchers have suggested that TC roots are nonfunctional and, therefore, must be replaced when plants are acclimated (Davis et al., 1977; Debergh and Maene, 1981; Maene and Debergh, 1983; Pierik 1987; Read and Fellman, 1985). Anatomical changes induced by the in vitro environment are a possible explanation for this lack of TC-formed root survival, but observations made in the present study do not support this hypothesis.

Poor success during plantlet acclimatization has been attributed, in part, to weak vascular development at the root-to-shoot interface (Conner and Thomas, 1981; Pierik, 1987; Ziv, 1986). However, TC explants and MACRO cuttings of Asian jasmine of the same ontogenetic age had similarly developed root-to-shoot vascular connections, a result reinforcing other less-detailed reports that failed to detect vascular discontinuity (Gronroos and von Arnold, 1985; Hicks, 1987; Mohammed et al., 1989; Patel et al., 1986). The companion paper of our study comparing root physiology and ${ }^{32} \mathrm{P}$ uptake supports these developmental observations (Apter et al., 1993). Apparently, adventitious root anatomy of TC Asian jasmine was not adversely influenced by the TC environment.

SEM. We used SEM to characterize root hairs and the external surface characteristics of TC and MACRO adventitious roots of Asian jasmine. No apparent morphological differences existed between roots sampled on Days 13 and 18. However, root hairs produced under TC conditions were one-third to one-half as long as those occurring under MACRO conditions (Fig. 2). Morphologically, MACRO root hairs, were long, thin, almost wiry, and

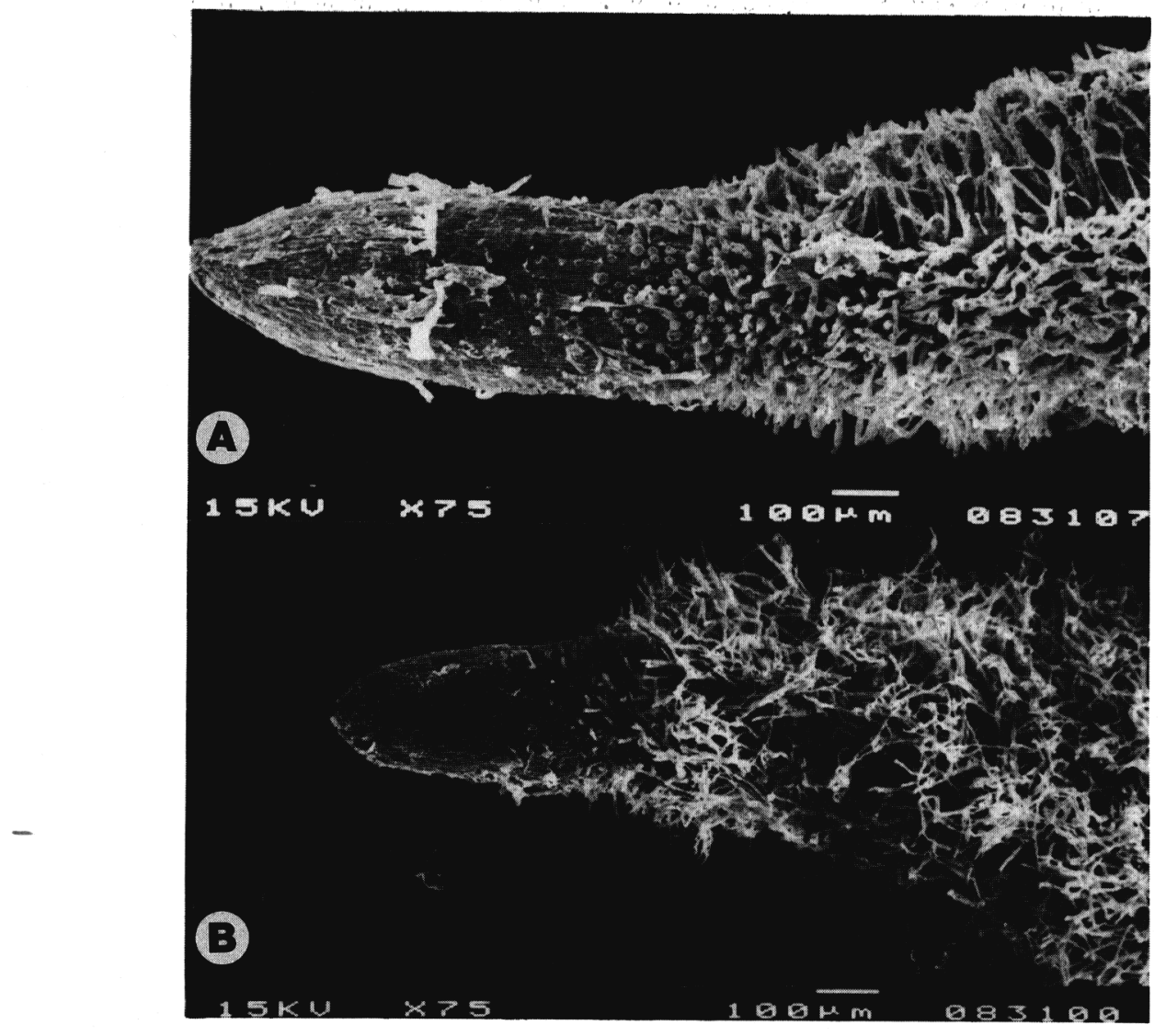

Fig. 2. Day 13: scanning electron microscopy micrographs of Asian jasmine showing root hair development of adventitious roots formed under (A) tissue culture and (B) macropropagation conditions. 
interwoven as a mat. TC root hairs were shorter, thicker, and straight. There were no apparent differences in the distance from the root tip to root-hair zone between treatments. While not quantified, root-hair density did not seem to differ significantly between the two propagation systems.

The presence of shorter root hairs on TC-formed roots could have significant implications for acclimatization of TC-produced plant material. Root hairs play an important role in the rhizosphere, effectively increasing root surface area; similarly, water uptake is made more effective by the presence of root hairs (Kramer, 1983). The shortened length or absence of root hairs on TC-formed roots could render those roots less functional to the plantlet, increasing the stress imposed during and after acclimatization. Roots grown in agar frequently have few or no root hairs, and those present can die after transplanting, causing loss of plantlets or cessation of their growth (Preece and Sutter, 1991). McKeand and Allen (1984) compared nutrient uptake ( $\mathrm{N}$ and $\mathrm{P}$ ) by $\mathrm{TC}$-formed and seedling roots of identical age of loblolly pine (Pinus taeda L.) after a 4week acclimatization. Nutrient uptake rates for TC plantlets were less than those for seedlings, when reported on a dry weight basis. Based on an estimate of volume surface area, however, uptake rates were similar. It is not clear whether root-hair differences were considered, but the presence of shorter root hairs on TC plantlets could affect the rate of nutrient uptake compared to seedling roots.

\section{Literature Cited}

Apter, R.C., F.T. Davies, Jr., and E.L. McWilliams. 1993. In vitro and ex vitro adventitious root formation in Asian jasmine (Trachelospermum asiaticum). II. Physiological comparisons. J. Amer. Soc. Hort Sci. 118:906-909.

Brainerd, K.E., L.H. Fuchigami, S. Kwiatkowski, and C.S. Clark. 1981. Leaf anatomy and water stress of aseptically cultured 'Pixy' plum grown under different environments. HortScience 16:173-175.

Conner, A.J. and M.B. Thomas. 1981. Re-establishing plantlets from tissue culture: A review. Proc. Intl. Plant Prop. Soc. 31:342-357.

Davies, F.T., Jr., J.E. Lazarte, and J.N. Joiner. 1982. Initiation and development of roots in juvenile and mature leaf bud cuttings of Ficus pumila L. Amer. J. Bot. 69:804-811.

Davis, M.J., R. Baker, and J.J. Hanan. 1977. Clonal multiplication of carnation by micropropagation. J. Amer. Soc. Hort. Sci. 102:48-53.

Debergh, D.L. and L.J. Maene. 1981. A scheme for commercial propagation of ornamental plants by tissue culture. Scientia Hort. 14:335-345.

Donnelly, D.J. and W.E. Vidaver. 1984a. Leaf anatomy of red raspberry transferred from culture to soil. J. Amer. Soc. Hort. Sci. 109:172-176. Donnelly, D.J. and W.E. Vidaver. 1984b. Pigment content and gas exchange of red raspberry in vitro and ex vitro. J. Amer. Soc. Hort. Sci. 109:177-181.

Donnelly, D.J., W.E. Vidaver, and K.Y. Lee. 1985. The anatomy of tissue cultured red raspberry prior to and after transfer to soil. Plant Cell Tissue Organ Cult. 4:43-50.

Esau, K. 1977. Anatomy of seed plants. 2nd ed. Wiley, New York.

Gronroos, R. and S. von Arnold. 1985. Initiation and development of wound tissue and roots on hypocotyl cuttings of Pinus sylvestris in vitro. Physiol. Plant. 64:393-401.

Grout, B.W.W. and M.J. Aston. 1977. Transplanting of cauliflower plants regenerated from meristem culture. I. Water loss and water transfer related to changes in leaf wax and to xylem regeneration. Hort. Res. 17:1-7.

Hartmann, H.T., D.E. Kester, and F.T. Davies, Jr. 1990. Plant propagationPrinciples and practices. 5th ed. Prentice-Hall, Englewood Cliffs, N.J.

Hicks, B.S. 1987. Adventitious rooting of apple microcuttings in vitro: An anatomical study. Can. J. Bot. 65:1913-1920.

Kramer, P.J. 1983. Water relations of plants. Academic Press, New York. Lloyd, G.B. and B. McCown. 1980. Commercially feasible micropropagation of mountain laurel, Kalmia latifolia, by use of shoottip culture. Proc. Intl. Plant Prop. Soc. 30:421-427.

Maene, L.M. and P.C. Debergh. 1983. Rooting of tissue cultured plants under in vivo conditions. Acta Hort. 131:201-208.

McKeand, S.E. and H.L. Allen. 1984. Nutritional and root development factors affecting growth of tissue culture plantlets of loblolly pine. Physiol. Plant. 61:523-528.

Mohammed, G.H., K.R. Patel, and W.E. Vidaver. 1989. The control of adventitious root production in tissue-cultured Douglas-fir. Can. J. For. Res. 19:1322-1329.

Patel, K.R., C. Rumary, and T.A. Thorpe. 1986. Plantlet formation in black and white spruce. III. Histological analysis of in vitro root formation and the root-shoot union. N.Z.J. For. Sci. 16:289-296.

Pierik, R.L.M. 1987. In vitro culture of higher plants. Martinus Nijhoff, Dordrecht, The Netherlands.

Preece, J.E. and E.G. Sutter. 1991. Acclimation of micropropagated plants to the greenhouse and field, p. 71-93. In: P.C. Debergh and R.H. Zimmerman (eds.). Micropropagation, technology and application. Kluwer Academic Publishers, Dordrecht, The Netherlands.

Read, P.E. and C.D. Fellman. 1985. Accelerating acclimation of in vitro propagated woody ornamentals. Acta Hort. 166:15-20.

Smith, M.A.L., J.P. Palta, and B.H. McCown. 1986. Comparative anatomy and physiology of microcultured, seedling, and greenhouse-grown Asian white birch. J. Amer. Soc. Hort. Sci. 111:437-442.

Zimmerman, R.H. 1988. Micropropagation of woody plants: Post tissue culture aspects. Acta Hort. 227:113-120.

Ziv, M. 1986. In vitro hardening and acclimatization of tissue culture plants, p. 187-196. In: L.A. Withers and P.G. Alderson (eds.). Plant tissue culture and its agricultural applications. Butterworths, London. 